\title{
Solid combined Sun-protective devises for windows with different orientation aspects in the conditions of hot and Sunny climate
}

\author{
Sergey Stetsky ${ }^{1, *}$, Irina Sokolova ${ }^{1}$ and Walid Abbas Hodeir ${ }^{1}$ \\ ${ }^{1}$ Moscow State University of Civil Engineering, Yaroslavskoeshosse 26, Moscow, 129337, Russia
}

\begin{abstract}
The article deals with the essential problems of Sun-protection by means of newly offered type of solid combined Sun-protective devices (S.P.D.) in the conditions of hot and Sunny climate, which is typical for the States of Near-East region namely for Lebanon and Syria. The solid combined S.P.D., which are under discussion in the article presented have the geometrics, which follow the Sun path over the sky vault, thus having a non-traditional curved outlines. It is stated, that they not only satisfy a sunprotection requirements efficiently, but also add an aesthetic qualities to the facades of buildings considered. In the article the calculations of geometrics for the S.P.D. in question for different orientation aspects of windows are given. These devices can improve the energy efficiency of the building.
\end{abstract}

\section{Introduction}

In series of former scientific studies, conducted by the staff of Chair of "Design of Buildings and Structures" of Moscow State University of Civil Engineering and number of post-graduates, a basic concept was adopted. [3-7, 13]

According to this concept, the Sun path along the sky vault should dictate the efficient geometry of external Sun-protective device (S.P.D.). The curvilinear Sun trajectory determines the form and shape of a S.P.D. required. Hence, the most efficient type of external S.P.D. should be:

i/ - of combined type, i.e. consisting of horizontal portion in form of a canopy and vertical portion in form of ribs (screens);

ii/ - of curvilinear form of all the separate portions of it;

iii/ - of different forms and shapes in connection with the orientation aspects of windows.

This scientific concept adopted was based on a series of scientific studies, conducted during the last decades by Soviet, Russian and foreign researchers [1, 2, 8-11].

In earlier-published works the authors determined the problem and calculated the geometrical parameters of the simplest case of solid combined S.P.D., which is the one over the windows of southern aspect of orientation. This article is devoted to a more complex cases, which corresponds to south-east and south-west orientation aspect of windows.

\footnotetext{
* Corresponding author: sergioni1947@gmail.com
} 


\section{Theoretical background}

As for, as the previous investigations were devoted to conditions of Syria and Lebanon, the article presented deals with the same countries. The territories of these states are situated within the range of $32,5^{\circ}$ and $37^{\circ}$ of Northern latitude. The most populated regions in the countries are situated in their southern and northern parts, where lay the most principal cities: Damascus, Beirut, Latakia and Aleppo.

We assume the average latitude as $33,5^{\circ}-34^{\circ}$, which corresponds to the latitude of Beirut and Damascus.For these cities the higher position of the Sun during summer, which features the higher outdoor temperature and higher amount of Sun radiation are as follows [8-10].

i/ - June $79,4^{\circ}$ at noon;

ii/ - July $76,5^{\circ}$ at noon;

iii/ - August $70,2^{\circ}$ at noon.

The summer temperatures in the region considered are as follows [8-10,12].

i/ - June: average $25,1^{\circ} \mathrm{C}$, maximum $38,9^{\circ} \mathrm{C}$;

ii/ - July: average $27,2^{\circ} \mathrm{C}$, maximum $42,2^{\circ} \mathrm{C}$;

iii/ - August: average $27,6^{\circ} \mathrm{C}$, maximum $45,0^{\circ} \mathrm{C}$;

Hence, the worst cases from a thermal and solar insulation points of views should be assumed for July and August. As far, as we study only the matter of Sun protection, we will not consider the thermal data, but concentrate on Sun-protective devices only. For the cases studied: we base on the materials of the previous investigations, which dealt with the southern orientation aspect of windows only. The new stage of study is devoted to southeast and south-west orientation aspects of windows and for this case we assume an average height of the Sun as $\mathrm{H} 0=72,0$ which will be a design value for geometry calculations. The basic design scheme for determination the geometric of a solid combine S.P.D. and isometric view of the S.P.D., offered in previous investigations are shown on Figures 1 and $2[3-11,13]$.

\section{The latter studies conducted and their results}

With the methodics, adopted before, the geometry of S.P.D. in question can be determined, using basic formulas (1-4), design scheme on Figure 3, and information data, in Tables 1 and 2. For a S.P.D. in question which can be considered as a combination of horizontal and vertical parts, the following design formulas are used [8-11]:

- For horizontal part of the S.P.D.:

$$
\begin{gathered}
\operatorname{tg} \beta=\frac{\mathrm{L}_{\mathrm{c}}}{\mathrm{H}_{\mathrm{c}}} \\
\mathrm{L}_{\mathrm{c}}=\mathrm{H}_{\mathrm{c}} \cdot \operatorname{tg} \beta
\end{gathered}
$$

- For vertical part of the S.P.D.:

$$
\begin{aligned}
& \operatorname{tg} \gamma=\frac{2 \mathrm{~L}_{\mathrm{s}}}{\mathrm{B}_{\mathrm{s}}} \\
& \mathrm{L}_{\mathrm{S}}=\frac{\operatorname{tg} \gamma \cdot \mathrm{B}_{\mathrm{S}}{ }^{\prime}}{2}
\end{aligned}
$$

Where:

$\mathrm{H}_{\mathrm{c}}$ - a distance from a window sill to a bottom of a canopy part of the S.P.D.;

$\mathrm{L}_{\mathrm{c}}-$ a projection of a canopy part of the S.P.D. from a wall;

$\mathrm{L}_{\mathrm{s}}$ - a projection of a screen part of the S.P.D. from a wall; 
$\mathrm{B}_{\mathrm{s}}-\mathrm{a}$ distance between screens of the S.P.D.;

$\mathrm{B}_{\mathrm{s}} / 2$ - a distance between a screen and the center of a window;

$\beta=90^{\circ}-\mathrm{H}_{0}-$ the shadowing angle of a canopy part of S.P.D.;

$\mathrm{H}_{0}$ - a design height of the Sun;

$\gamma=90^{\circ}-A_{0}-$ the shadowing angle of a screen part of S.P.D.;

$\mathrm{A}_{0}($ or $\alpha)$ - the universal azimuthal angle of a window with S.P.D.;

$\alpha$ - the specific azimuthal angle to be determined from a line of a real direction of a window' orientational aspect;

$\mathrm{M}$ - the design insolation point of a window.

The design scheme, presented on Figure 3 is made for the case of south-eastern orientation aspect of a window; the design scheme for south-western orientation aspect is made with use of the same formulas and rules and looks like a mirror version of this the scheme presented.

As an example, we consider a real case of a S.P.D. with south-eastern orientation aspect over a window, using the data of Table 1. The initial geometrics are as follows:

i/ - width of a window $\mathrm{B}_{\mathrm{w}}=1,8 \mathrm{~m}$

ii/ - height of a window $\mathrm{H}_{\mathrm{w}}=1,8 \mathrm{~m}$

iii/ - thickness of the wall $\delta_{\mathrm{w}}=0,25 \mathrm{~m}$

iv/ - the distance between a lintel of the window and bottom part of the S.P.D. (height of a canopy over a lintel) $\mathrm{H}_{\mathrm{cw}}=0,2 \mathrm{~m}$

$\mathrm{v} / \mathrm{-}$ the distance between screens of S.P.D. and window opening $\mathrm{B}_{\mathrm{cw}}=0,2 \mathrm{~m}$

$\mathrm{vi} /$ - the design insolation point of a window.

The exact design data for geometric parameters front views, plans, cross sections and isometricos of newly-offered S.P.D. are presented in tables 1 and 2 and on of Figures 3,4,5.

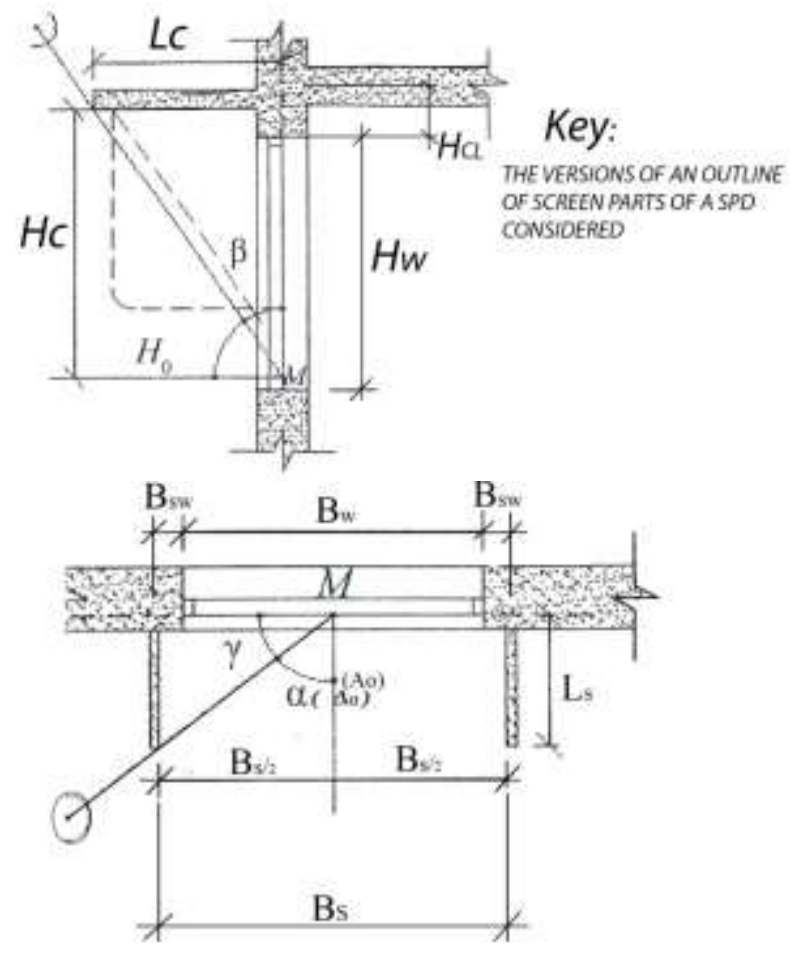

Fig. 1. A design scheme for determination of geometrical parameters of solid combined S.P.D. over the window with southern orientation aspect in climatic conditions of Damascus and Beirut. 


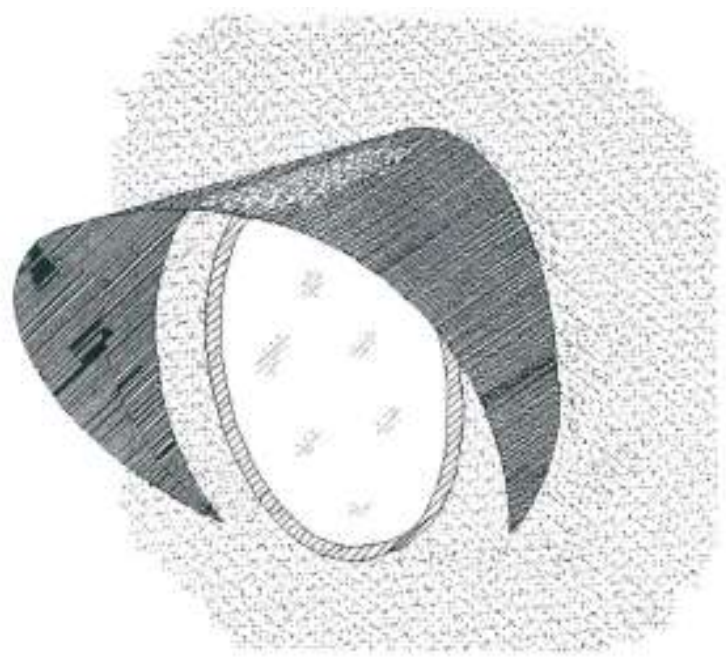

Fig. 2. An isometric view of a solid combined S.P.D. for southern orientation aspect (former proposed design solution).

Note. The S.P.D. shown is situated over a window of circular shape, which was chosen to match the solid, round form of the S.P.D.

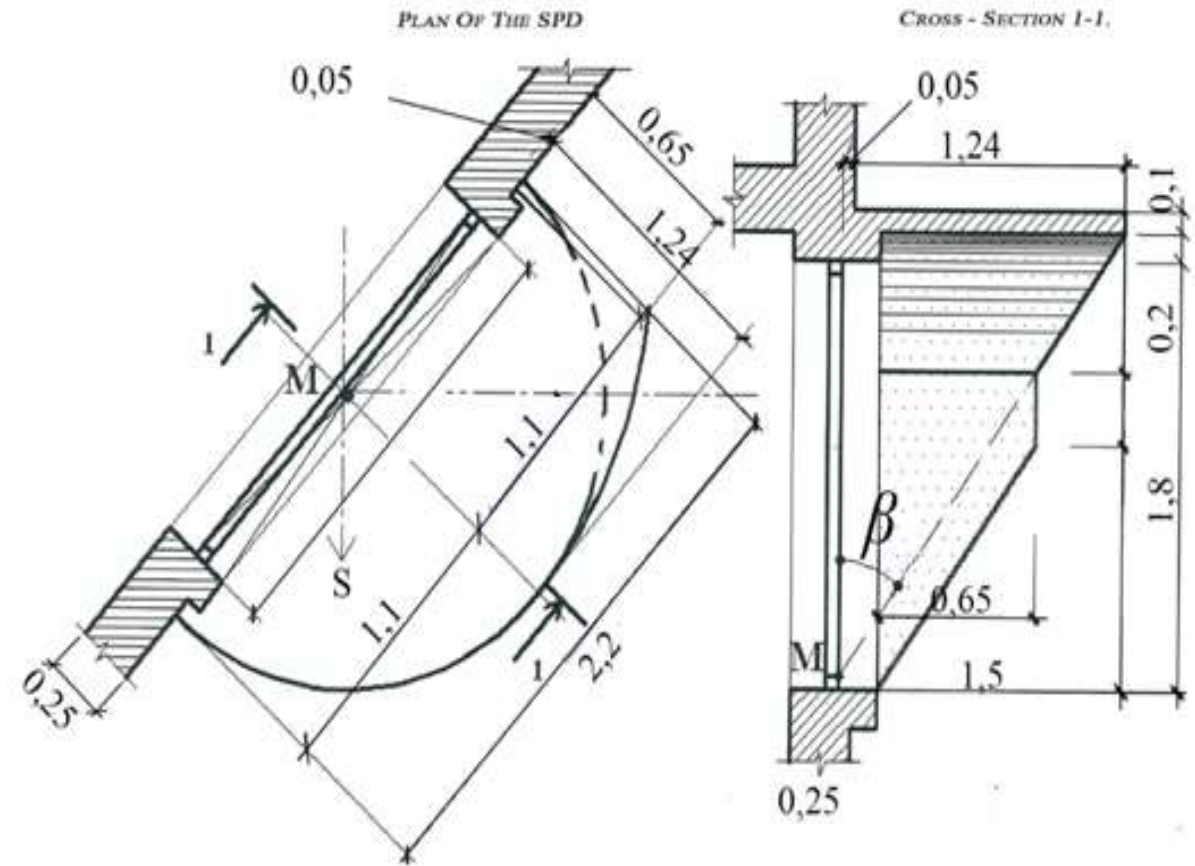

Fig. 3. A design scheme for determination of geometrical parameters of solid combined S.P.D. over a window of south-eastern orientation aspect in climatic conditions of Damascus and Beirut. 
Table 1. Geometrical parameters (in general form) for the solid combined curvilinear S.P.D. for the conditions of Damascus and Beirut.

\begin{tabular}{|c|c|c|c|c|c|c|}
\hline \multirow{2}{*}{ : } & \multirow{2}{*}{ 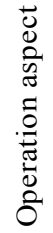 } & \multirow{2}{*}{ 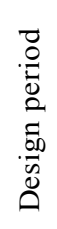 } & \multicolumn{4}{|c|}{ Azimuth angles and height of the sun for certain hours of a day. (Average) } \\
\hline & & & 6 am and $18 \mathrm{pm}$ & 8 am and $16 \mathrm{pm}$ & 10 am and $14 \mathrm{pm}$ & Noon \\
\hline 1 & 2 & 3 & 4 & 5 & 6 & 7 \\
\hline \multirow{7}{*}{$\begin{array}{l}\dot{1} \\
\dot{Z} \\
\dot{0} \\
0 \\
\dot{0}\end{array}$} & \multirow{7}{*}{ 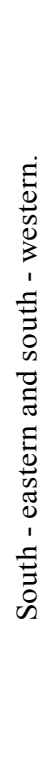 } & \multirow{7}{*}{ 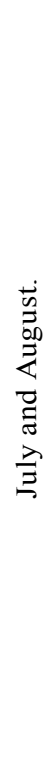 } & $\begin{array}{c}\mathrm{A}_{\mathrm{O}}=76^{\circ} \text { and } 284^{\circ} \\
\mathrm{H}_{\mathrm{O}}=9,0^{\circ}\end{array}$ & $\begin{array}{c}\mathrm{A}_{\mathrm{O}}=95^{\circ} \text { and } 265^{\circ} \\
\mathrm{H}_{\mathrm{O}}=32^{\circ}\end{array}$ & $\begin{array}{c}\mathrm{A}_{\mathrm{O}}=115^{\circ} \text { and } 245^{\circ} \\
\mathrm{H}_{\mathrm{O}}=58^{\circ}\end{array}$ & $\begin{array}{c}\mathrm{A}_{\mathrm{O}}=180^{\circ} \\
\mathrm{H}_{\mathrm{O}}=72^{\circ}\end{array}$ \\
\hline & & & \multicolumn{4}{|c|}{ Design angles for certain hours of a day. } \\
\hline & & & $\begin{array}{l}\beta=81^{0} \\
\alpha=59^{\circ} \\
\gamma=31^{0}\end{array}$ & $\begin{array}{l}\beta=58^{\circ} \\
\alpha=40^{\circ} \\
\gamma=50^{\circ}\end{array}$ & $\begin{array}{l}\beta=32^{\circ} \\
\alpha=20^{\circ} \\
\gamma=70^{\circ}\end{array}$ & $\begin{array}{c}\beta=18^{\circ} \\
\alpha=-45^{\circ} \\
\gamma=135^{\circ}\end{array}$ \\
\hline & & & \multicolumn{4}{|c|}{ Trigonometrical functions of angles for certain hours of a day. } \\
\hline & & & $\begin{array}{c}\operatorname{tg} \beta=37,3 \\
\cos \alpha=0,52 \\
\operatorname{tg} \gamma=0,6\end{array}$ & $\begin{array}{c}\operatorname{tg} \beta=1,6 \\
\cos \alpha=0,77 \\
\operatorname{tg} \gamma=1,19\end{array}$ & $\begin{array}{c}\operatorname{tg} \beta=0,62 \\
\cos \alpha=0,97 \\
\operatorname{tg} \gamma=2,74\end{array}$ & $\begin{array}{c}\operatorname{tg} \beta=0,32 \\
\cos \alpha=0,71 \\
\operatorname{tg} \gamma=3,5\end{array}$ \\
\hline & & & \multicolumn{4}{|c|}{ Geometrioal parameters of the SPD for certain hours of a day. } \\
\hline & & & $\begin{aligned} \mathrm{Lc} & =37,3 \mathrm{~m} \\
\mathrm{Ls} & =0,66 \mathrm{~m}\end{aligned}$ & $\begin{array}{c}\mathrm{Lc}=3,2 \mathrm{~m} \\
\mathrm{Ls}=1,31 \mathrm{~m}\end{array}$ & $\begin{array}{c}\mathrm{Lc}=1,24 \mathrm{~m} \\
\mathrm{Ls}=3,0 \mathrm{~m}\end{array}$ & $\begin{array}{c}\mathrm{Lc}=0,64 \mathrm{~m} \\
\mathrm{Ls}=3,9 \mathrm{~m}\end{array}$ \\
\hline
\end{tabular}


Table 2. Geometric parameter in reality of solid combined S.P.D. for a given window, climate and orientation aspect.

\begin{tabular}{|c|c|c|c|c|}
\hline \#\# & $\begin{array}{c}\text { The general } \\
\text { dimensions of a } \\
\text { window and a wall. }\end{array}$ & $\begin{array}{c}\text { Hours of a } \\
\text { day. }\end{array}$ & $\begin{array}{c}\text { The main dimensions } \\
\text { of SPD with south - } \\
\text { eastern orientation } \\
\text { aspect. }\end{array}$ & $\begin{array}{c}\text { The main dimensions } \\
\text { of SPD with south - } \\
\text { western orientation } \\
\text { aspect. }\end{array}$ \\
\hline 1 & 2 & 3 & 4 & 5 \\
\hline 1 & $\begin{array}{l}\text { Thickness of the wall } \\
\qquad \delta \mathrm{w}=0,25 \mathrm{~m} .\end{array}$ & $6 \mathrm{am}$ & $\mathrm{Ls}=3,9 \mathrm{~m}$ & \\
\hline 2 & $\begin{array}{l}\text { Width of a window } \\
\qquad \mathrm{Bw}=1,8 \mathrm{~m}\end{array}$ & 8 am & $\mathrm{Lc}=3,2 \mathrm{~m}$ & \\
\hline 3 & $\begin{array}{l}\text { Height of a window } \\
\qquad \mathrm{Hw}=1,8 \mathrm{~m}\end{array}$ & $10 \mathrm{am}$ & $\mathrm{Lc}=1,44 \mathrm{~m}$ & \\
\hline 4 & $\begin{array}{l}\text { Averade distance } \\
\mathrm{Hcw}, \mathrm{Bsw}=0,2 \mathrm{~m}\end{array}$ & Noon & $\mathrm{Lc}=0,64 \mathrm{~m}$ & $\mathrm{Lc}=0,64 \mathrm{~m}$ \\
\hline 5 & $\begin{array}{l}\text { Height of SPD Hc }= \\
1,8+0,2=2,0 \mathrm{~m}\end{array}$ & $14 \mathrm{pm}$ & & $\mathrm{Lc}=1,44 \mathrm{~m}$ \\
\hline 6 & $\begin{array}{l}\text { Width of SPD Bs } / 2= \\
\qquad 1,1 \mathrm{~m} .\end{array}$ & $16 \mathrm{pm}$ & & $\mathrm{Lc}=3,2 \mathrm{~m}$ \\
\hline 7 & $\begin{array}{l}\text { Thickness of window } \\
\text { block } \quad \delta w B=0,05\end{array}$ & $18 \mathrm{pm}$ & & $\mathrm{Ls}=3,9 \mathrm{~m}$ \\
\hline 8 & \multicolumn{4}{|c|}{ The thickness of canopy and screen $\delta \mathrm{c}=\delta \mathrm{s}=0,1 \mathrm{~m}$. } \\
\hline 9 & \multicolumn{4}{|c|}{$\begin{array}{l}\text { The distance between design pant "M" and the outer surface of the wall } \\
\qquad \delta \mathrm{M}=0,1 \mathrm{~m} .\end{array}$} \\
\hline
\end{tabular}

\section{A - FOR SOUTH - EASTERN ORIENTATION ASPECT}

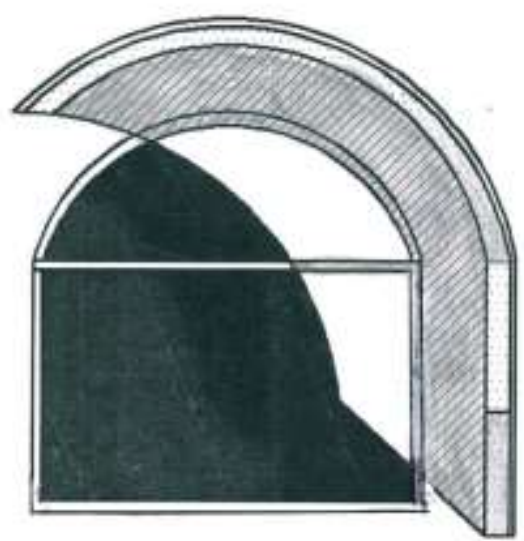

B - FOR SOUTH - WESTERN ORIENTATION ASPECT

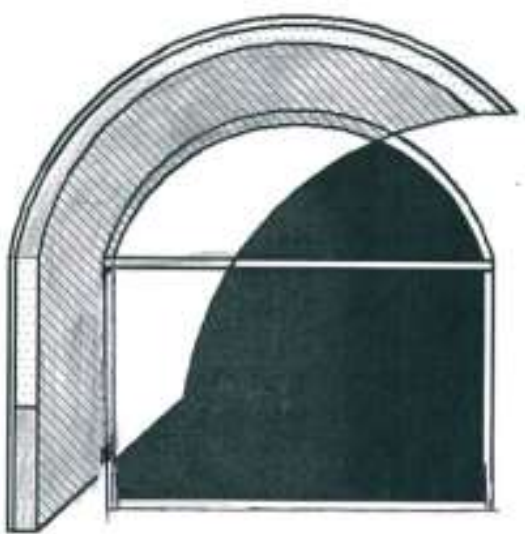

Fig. 4. Frontal views of solid combined S.P.D. over windows with orientation aspect on the southern quarter of the horizon. 

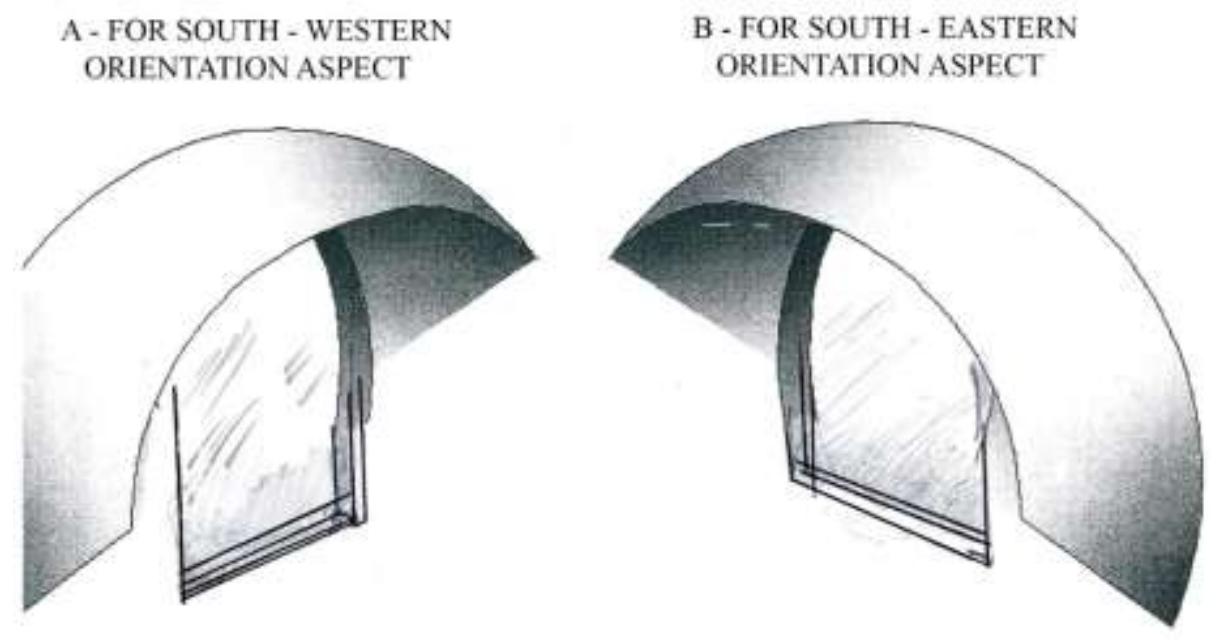

Fig. 5. An isometric news of proposed design solution of solid combined S.P.D.

As one can see from the data of Tables 1 and 2, the geometrics of the S.P.D. in some points are too big, not suitable for normal practical use.

That's why an engineering decision has been adopted, which adopts the average geometrics. The final geometric solution of the S.P.D. considered is shown on Figure 3.

\section{Conclusions}

A principally new type of external stationary S.P.D. has been offered. This one is a modified version of traditional combined S.P.D. with use of curvilinear planes as canopy and screen parts. The overall shape of S.P.D. offered is based on trajectory of the Sun motion along the sky vault. The proposed S.P.D. forms are designed for different windows aspect of orientation within the southern quarter of the horizon from south-east to southwest.

To determine the design geometrics of the S.P.D. in question, it is necessary to determine a position of the Sun during a day hours for the most hot months of a year, which for the conditions of Syrian an Lebanon capitals are July and August. In connection with curvilinear shape of the S.P.D. discussed, the window openings should have a semi-circular upper parts to match the S.P.D. configuration.

The new type of the S.P.D. discussed opens the new possibilities not only in the design of efficient Sun protection and lowering the thermal gains in the interiors due to the excessive Sun radiation, but also in the design of indoor natural lighting environment, due to the incorporation of the S.P.D.surfaces in the process of Sun rays' reflection in the "clear sky" conditions, which are typical to the Lebanon and Syrian Sunny climate.

\section{References}

1. A.K. Soloviev, Svetotechnika 7, 14-16 (1987)

2. M.Y. Mitnik, A.V. Spiridonov, Svetotechnika 10, 16-19 (1990)

3. S.V. Stetsky, V.A. Hodeir, Vestnik MGSU 7, 9-15 (2012)

4. S.V. Stetsky, V.A. Hodeir, Vestnik MGSU 8, 39-45 (2012) 
5. S.V. Stetsky, V.A. Hodeir, PGS 6, 71-73 (2013)

6. S.V. Stetsky, Nauchnoeobozrenie 21, 54-58 (2016)

7. S.V. Stetsky, M.A. Salo, SMOT of XXI century 10, 64-66 (2004)

8. A.K. Soloviev, Physics of the environment (AS publishers, Moscow, 2008)

9. N.M. Gusev, Fundamentals of Building Physics (Stroyizdat, Moscow, 1975)

10. M. Tvarovsky, Sun in architecture (Stroyizdat, Moscow, 1977)

11. E. Harkness, M. Mehta, The control of solar radiation in buildings (Stroyizdat, Moskow, 1984)

12. E.P. Borisenko, A short reference book on climate for the world' countries (Gidrometeoizdat, Leningrad, 1988)

13. V.A. Hodeir, The efficient Sun-protection devices in residential construction of Lebanon, A report on the Conference of Young Scientists (MGSU, Moscow, 2011)

14. Blinds and shutters-thermal and visual comfort performance, characteristics and classification. European Standard (European Committee for Standardization, Brussel, 2012)

15. Solar shading for low energy buildings (European Solar Shading Organization. Brussel, 2012)

16. "Understanding overheating - where to start?" A guide for home builders and designers (NHB Foundation, Milton Keynes, England, 2012) 